$4-24-2020$

\title{
Leadership Roles in the Field of Occupational Therapy
}

Christina Pitts

University of St. Augustine for Health Sciences

DOI: https://doi.org/10.46409/sr.SNQM7186

Follow this and additional works at: https://soar.usa.edu/capstones

Part of the Leadership Studies Commons, and the Occupational Therapy Commons

\section{Recommended Citation}

Pitts, C. (2020). Leadership Roles in the Field of Occupational Therapy. [Doctoral project, University of St Augustine for Health Sciences]. SOAR @ USA: Student Capstone Projects Collection. https://doi.org/ $10.46409 /$ sr.SNQM7186

This Capstone is brought to you for free and open access by the Student Research at SOAR @ USA. It has been accepted for inclusion in Student Capstone Projects by an authorized administrator of SOAR @ USA. For more information, please contact soar@usa.edu, erobinson@usa.edu. 
LEADERSHIP IN THE FIELD OF OCCUPATIONAL THERAPY

by

\author{
Christina Pitts
}

A Capstone Presented in Partial Fulfillment of the Requirement for the Degree of DOCTOR OF OCCUPATIONAL THERAPY

University of St. Augustine for Health Sciences

April 2020 


\title{
LEADERSHIP IN THE FIELD OF OCCUPATIONAL THERAPY
}

\author{
by
}

Christina Pitts

has been approved

April 2020

APPROVED:

Kayla Collins, EdD, OTR/L, Doctoral Coordinator

Thais Petrocelli, OTD, OTR/L, Doctoral Coordinator

Mary Shotwell, PhD, OT/L, Program Director

ACCEPTED AND SIGNED:

Kayla Collins

Kayla Collins, EdD, OTR/L, Doctoral Coordinator

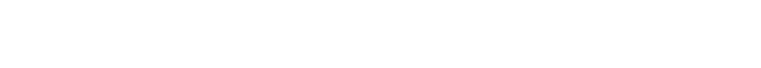

Thais Petrocelli, OTD, OTR/L, Doctoral Coordinator

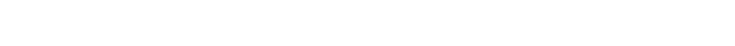

FAOTA
Mary Shotwell, PhD, OT/L, Program Director 
Table of Contents

Chapters $\quad \underline{\text { Pages }}$

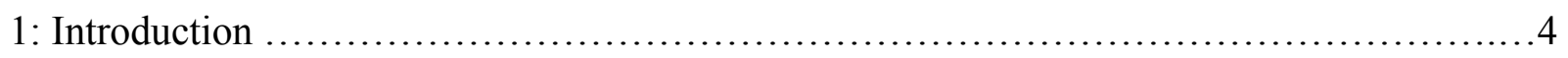

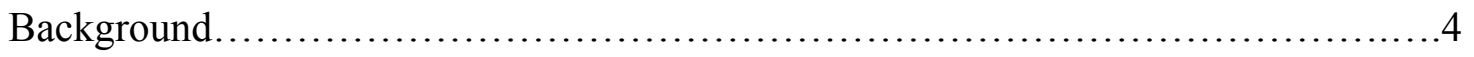

Statement of the Problem...........................................................

Purpose Statement ..................................................... 7

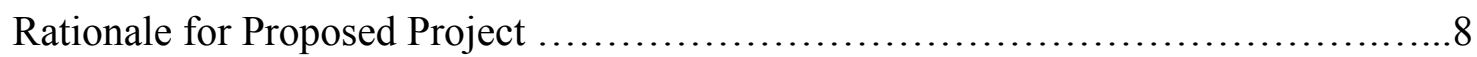

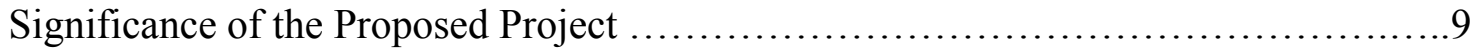

Preliminary Project Objectives ............................................

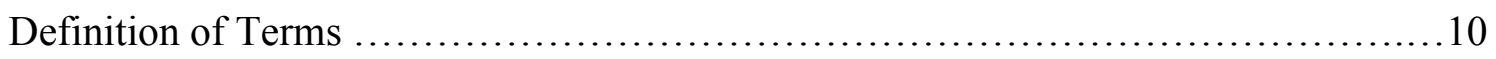

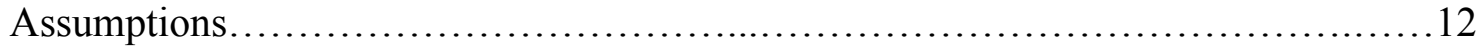

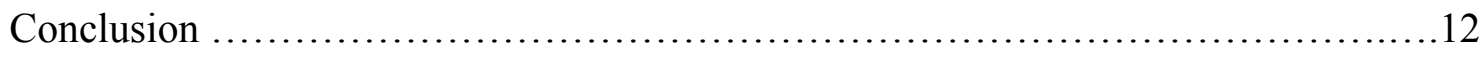

2: Literature Review ....................................................... 13

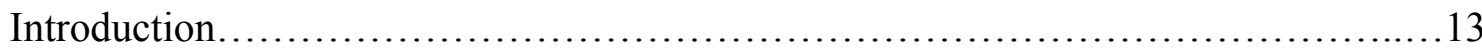

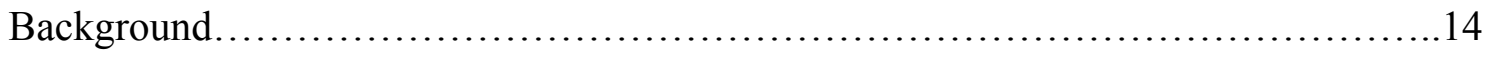

Leadership in Occupational Therapy...................................... 16

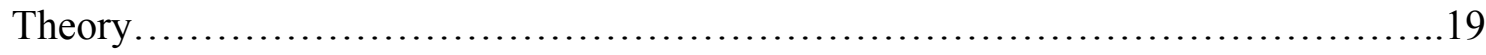

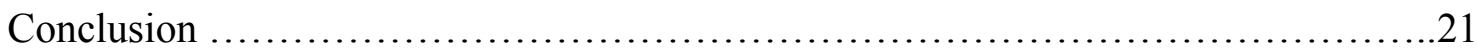

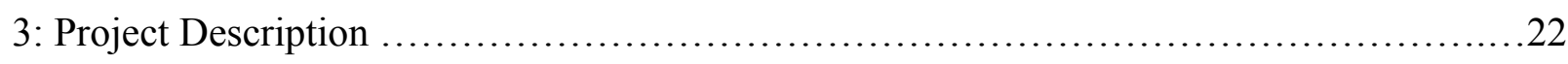

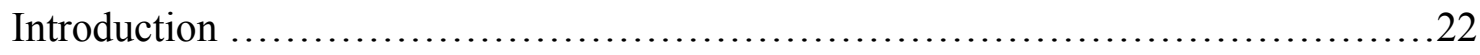

Process/Methods .......................................................24

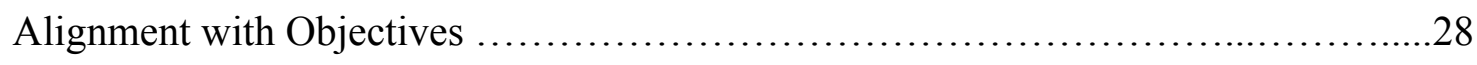

Conceptual Framework ....................................................29

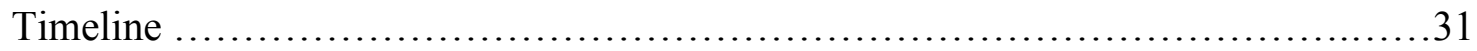

Envisioned Next Steps ................................................... 33

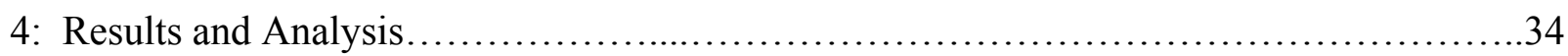

Measurement of Effectiveness................................................. 37

Results/Discussion ...................................................40

Limitations and Delimitations ............................................43

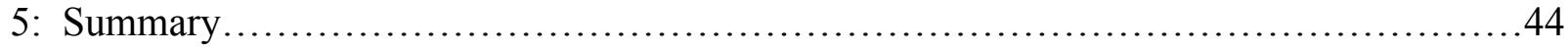

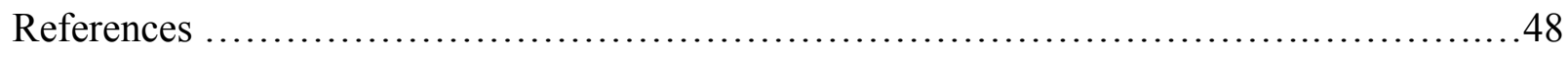




\section{Chapter I: Introduction}

A leader is not just someone who has a management position, but someone who goes "against the status quo to develop new relationships and transform already existing cultures to achieve sustainable change" (Fleming-Castaldy \& Patro, 2012, p. 188). Leadership roles can be formal, those individuals with authority and title, as well as informal, including those who "play a key role in enabling, influencing, and guiding others in the work environment" (Heard \& Scott, 2018, p. 1). Occupational therapists are capable and able to be leaders but do so less than other professionals. Breaking into leadership roles can be difficult, especially for new graduates (Braverman, 2016).

The American Occupational Therapy Association (AOTA, 2016) has been pushing for occupational therapists to be leaders in healthcare. A 2017 mandate, was later rescinded which would have required all entry-level occupational therapy programs to transition to the entry-level doctorate (AOTA, 2018). According to AOTA (2018), the Accreditation Council for Occupational Therapy Education (ACOTE) continues to support the entry-level doctorate, believing it is the appropriate admission point for the profession. The purpose of this proposal is to outline the goal for this capstone project, which is to demonstrate leadership through program development and implementation utilizing the leadership qualities identified as essential for OT leaders through experience and expertise. This paper includes an overview of the literature, problem statement, as well as the purpose, rationale, and significance of this capstone project, and objectives that are intended to be achieved.

\section{Background}

Truskowski (2017) defines leadership as an "active process of inspiring and developing people to achieve individual and organizational aims" (p. 1). Leadership is a crucial element in 
every profession; it contributes to the overall success of an organization at any level.

Occupational therapy leaders are those individuals who influence change for the profession and for individuals receiving services through advocacy, policy development, program development, education, and research (Fleming-Castaldy \& Patro, 2012). Heard (2014) reported that occupational therapists who have chosen the path of leadership did so to "participate in something new and to become more involved and have more of an impact" motivated by "the ability to influence change" in addition to career advancement (p. 7). Brown, Crabtree, Mu, and Wells (2015) found the American Occupational Therapy Association (AOTA) endorses occupational therapy transitioning to an entry-level doctorate because entry-level clinicians need to demonstrate professional autonomy to take on leadership positions within the healthcare system. The AOTA (2019) places great emphasis on the development of influential leaders within the profession. One of its five pillars for "AOTA's Vision 2025" is "leaders" (AOTA, 2019). The organization is making changes to encourage more occupational therapists, specifically entry-level practitioners, to demonstrate leadership within the profession. Despite the press within occupational therapy for clinicians to take on leadership roles, there is a lack of literature serving to illustrate the essential qualities occupational therapists in leadership possess (Fleming-Castaldy \& Patro, 2012). Information about these qualities will educate entry-level practitioners with the knowledge about potential steps they can take to become leaders in the field.

Lapointe, Baptiste, von Zweck, and Craik (2013) discussed how strong leadership is necessary in the field of occupational therapy stating, "leaders help push boundaries and champion advancements in practice, policy, research, and education to develop and promote client-centered, occupation-based enablement" (p. 38). Occupational therapy provides services 
that are pertinent to a broad range of patient populations. However, other health care professionals and insurance companies do not always view these services as necessary. The Medicare Home Health Flexibility Act (Doggett \& Smith, 2019) provides one example of how leadership can change the future of the profession. Currently, only nurses, physical therapists, and speech-language pathologists are allowed to open a home health case by performing an initial evaluation. However, legislation introduced in the House of Representatives on June 6, 2019, would allow occupational therapists to open home health therapy cases under Medicare (Bopp, 2019).

Although the profession of occupational therapy has existed for 100 years, it lags behind other rehabilitation professions in several areas, including leadership (Heard \& Scott, 2018). These problems are exacerbated by a lack of strong leadership positions, both formal and informal, held by individual occupational therapists. If not addressed, the lack of leaders in the field may lead to further declines in the occupational therapy profession, such as not being recognized as necessary providers in the healthcare system.

\section{Statement of the Problem}

Occupational therapy graduate programs want to prepare students to be competent clinicians upon graduation. However, the entry-level MOT curriculum and fieldwork components are lacking in areas that educate students on leadership, the qualities of an effective leader, and opportunities to engage in leadership roles (Smallfield, Flanigan, \& Sherman, 2019). The ACOTE's 2027 mandate requiring all entry-level occupational programs to transition to the doctorate level would have helped to bridge the leadership gap; however, the mandate was rescinded (AOTA, 2018). Thus, the problem of the current occupational therapy curriculum lacking education on leadership still exists and will continue to do so. 
To date, there is little to no literature on entry-level occupational therapists' role in leadership. Braverman (2016) described how occupational therapy students or entry-level practitioners generally do not see the importance of leadership because they are only concerned with patient care issues. As a result of these problems, the majority of entry-level clinicians do not demonstrate a leadership role in the field (Braverman, 2016).

The AOTA has taken steps to start bridging the gap regarding leadership in the current curriculum of most entry-level occupational therapy programs by advocating for entry-level doctorate programs. Currently, however, the entry-level doctorate is not a requirement, and there is still a lack of occupational therapy leaders in the field. Leadership, in addition to mentorship strategies and initiatives, is vital to successfully progress the profession of occupational therapy and improve access to our services (Lapointe, Baptiste, von Zweck, \& Craik, 2013). The lack of knowledge about leadership, mentors who are leaders, and awareness about the importance of leadership to the success of the profession contribute to the shortage of leaders in the field compared to other healthcare professionals.

Heard (2014) notes the participants, who held leadership roles in occupational therapy, reported that they did not seek out their leadership position but "fell into" it. The participants in this study recommended, "future leaders might be best supported via earlier inclusion of leadership content in occupational therapy curricula by linking professional performance and leadership potential..." (Heard, 2014, p. 13).

\section{Purpose Statement}

The purpose of this project was to demonstrate leadership through program development and implementation, utilizing the leadership qualities identified as essential for occupational therapy leaders through experience and expertise. Interviews with occupational therapists in 
leadership positions and assessment of professional development opportunities for new occupational therapy practitioners will provide an idea on how to get involved in leadership. This capstone project aimed to illustrate the attributes of occupational therapists in leadership and the potential steps entry-level practitioners can take to become leaders in the field.

Learning about leadership, determining common qualities that effective occupational therapy leaders possess, and having the opportunity to participate in a leadership role as a student or entry-level clinician will help form influential leaders that have the potential to change the profession through leadership roles.

\section{Rationale for Proposed Project}

From personal experience, conversing with peers in an occupational therapy program, and reviewing the literature, it is evident that many students and new graduates struggle with leadership because they are focusing on their new role as a clinician (Braverman, 2016). Entrylevel occupational therapists are transitioning into a new role from student to professional. In a study conducted by Toal-Sullivan (2006), entry-level occupational therapists reported, "their limited practical experience, the responsibilities of client care, system issues and role uncertainty" were challenges they faced when transitioning into their new role (p. 513). Breaking into leadership roles can be difficult, especially for entry-level practitioners (Braverman, 2016). Therefore, having the opportunity to learn about and demonstrate leadership will provide the knowledge and skills necessary to be an effective leader in the field.

Entry-level clinicians often associate leadership with a formal title that has administrative responsibilities within the job description (Heard and Scott, 2018). A leader does not always have a title (Heard \& Scott, 2018). A leader is anyone who ignites change within the field to advance the profession (Heard \& Scott, 2018). Examples include increasing education about a 
condition or improving the well-being of a client population through program development. Entry-level clinicians have the education and drive to create change within the field of occupational therapy, but lack the confidence and professional autonomy to do so (Brown, Crabtree, $\mathrm{Mu}, \&$ Wells, 2015). As future leaders in the field of occupational therapy, it is the role and duty of new graduates to take the initiative in advocating for our profession and provoking change.

\section{Significance of the Proposed Project}

Current didactic coursework in occupational therapy does not emphasize leadership roles in the healthcare field. Further, the majority of programs just requiring an entry-level master's degree. The AOTA supports the development of the entry-level doctorate program and has highlighted the importance of leadership in its Vision 2025 (AOTA, 2017).

Starting with new graduates provides a way to shift the profession more towards leadership. Entry-level OTD students also have the potential to change the field of occupational therapy through leadership. Encouraging occupational therapists to become leaders in the healthcare industry is vital to the profession. The field of occupational therapy needs more leaders to: 1) defend our patients' rights to services; 2) ensure clinicians are getting what they deserve regarding finances, health and well-being; and 3) advocate for the profession "to legislators for language and regulations that expand occupational therapy coverage and codify favorable definitions of terms such as medical necessity, eliminate service limits, and increase funding for programs that provide services for people with disabilities" (Stover, 2016). There is a push within occupational therapy for therapists to take the initiative, becoming leaders in the field to help guide the future of the profession (Fleming-Castaldy \& Patro, 2012).

\section{Preliminary Project Objectives}


Learning Objectives:

- Identify literature on leadership roles in the field of occupational therapy.

- Determine the essential qualities of leadership through interviews and observations of healthcare professionals who have leadership roles to demonstrate leadership qualities through program development.

Outcome Objectives:

- Collaborate with the owner of an outpatient Lifespan clinic and colleagues on program objectives and implementation to ensure long-term carryover of program materials and resources by the end of Week 4 .

- Implement a developed program with the guidance of at least two OTRs and management at Advent Therapy by the end of Week 8 through Week 14 .

- Monitor implementation of the program by observing, interviewing, and surveying staff and caregivers weekly.

- Evaluate the effectiveness of program implementation by interviewing, observing, and surveying staff and caregivers and obtaining written feedback from staff end of Week 14.

\section{Definition of Terms}

\section{Leadership}

Strong leadership in the healthcare field creates "structural sustainable changes that enable organizational success" and moves organizations forward (Fleming-Castaldy \& Patro, 2012, p. 188). As defined by Truskowski (2017), leadership is "the active process of influencing others to achieve common goals" (p. 12). The leader must creating a vision for an organization, align people with that vision through communication, and then motivate and empower those people to contribute to achieving that vision through collaborative efforts (Lunenberg, 2011). 
Those with formal titles, such as managers or directors, demonstrate leadership, but so do those without formal titles, including entry-level clinicians. Leaders focus on doing the right thing (Fleming-Castaldy \& Patro, 2012) to produce change that will benefit a larger population.

\section{Management}

A person who holds the title of a manager is not necessarily a leader. Fleming-Castaldy and Patro (2012) define management as the "organization, direction, and control of work to ensure the adequacy of its quality" (p. 188). Management involves planning and budgeting, organizing and staffing, and controlling and problem-solving (Lunenberg, 2011). Manager's concentrate on getting the task done to ensure the organization is running smoothly; they focus on maintenance, not on producing change or enhancing the organization (Fleming-Castaldy \& Patro, 2012).

\section{Program Development, Implementation, and Evaluation}

Program development is a process that involves many steps: needs assessment, program development, program implementation, and program evaluation (Fields, 2017). The first step is a needs assessment, which is conducted to identify the needs, or gaps, in an organization. This information is used to determine what type of program will best help the organization. The process continues with identifying resources, prioritizing program features based off of recourses and characteristics of the target population, creating goals and specific objectives to meet those goals, and selecting methods and a setting that will best meet the objectives (Fields, 2017). Program implementation is the next step, which consists of carrying out the program developed in the previous step. Lastly, program evaluation is done by selecting a validated program evaluation tool, assessing the program processes, and using these findings to assess the program impact and the need for modifications (Fields, 2017). 


\section{TeamSTEPPS 2.0}

The DoD and AHRQ (2012) developed TeamSTEPPS 2.0, an evidence-based teamwork program designed to optimize patient outcomes by improving communication and teamwork skills among healthcare professionals. TeamSTEPPS 2.0 organizes the process into ten steps (DoD \& AHRQ, 2012). These have been modified and adjusted to fit the needs of this capstone project.

\section{Assumptions}

For this capstone project, we assumed that the children of caregivers who participated in the program lacked knowledge about developmental milestones, which created stress for the parents/caregivers of preschool- and school-aged children. Also, it was assumed the resources for creating the program were available and adequate; curriculum on developmental milestones was developed and delivered effectively; and the therapists at Advent Therapy were willing and able to contribute.

\section{Conclusion}

Occupational therapy lags behind other rehabilitation professionals in many areas, likely due to a lack of research literature supporting leadership and of strong leadership demonstrated within the field. The AOTA is continuously demonstrating a push to develop influential leaders within the profession. It emphasized the importance of leadership to achieve the goals outlined in AOTA's Vision 2025 (AOTA, 2019). The current entry-level OT curriculum lacks education on leadership and opportunities for students to demonstrate leadership within the field (Smallfield, Flanigan, \& Sherman, 2019). This capstone project addressed this issue by providing occupational therapy students and entry-level clinicians with attributes of occupational therapists 
in leadership and the potential steps entry-level practitioners can take to become leaders in the field.

\section{Chapter II: Literature Review}

This literature review begins with a brief history of the foundation of occupational therapy and discusses past and current leadership theories. Second, literature from leadership roles in occupational therapy is synthesized to identify gaps within the literature and to develop an understanding of leadership within the field. The review concludes with a description of the theoretical framework guiding this study.

\section{Background}

\section{Brief History of Occupational Therapy}

A strong recognition for the importance of occupational therapy in the United States began during World War I with the appointment of Reconstruction aids, who worked alongside nurses to distract the injured, increase morale, and increase physical activity (AOTA, 2017). Throughout the nineteenth century, the influence of moral treatment and the arts and crafts movement inspired physicians, social workers, and nurses to use occupation-based activities to engage the minds and hands of patients (AOTA, 2017). The National Society for Promotion of Occupational Therapy, now known as the American Occupational Therapy Association (AOTA), was established in the United States in 1917, recognizing occupational therapy as a profession; in 1920 Occupational Therapy became the official name of the profession in 1920 (AOTA, 2017). The first recognized leaders in the occupational therapy profession include George Edward Barton, William Rush Dunton, Jr., Susan Cox Johnson, Thomas Bessell Kidner, Isabel G. Newton, and Eleanor Clarke Slagle (AOTA, 2017). Each of these leaders contributed to the establishment of the profession of occupational therapy by empowering each other and others 
through advocacy, collaborative efforts, and innovative ideas to create change. Throughout the past century, occupational therapy has grown to become an essential profession in the healthcare field, helping to provide rehabilitative services to individuals with mental, physical, or developmental impairments because of the contribution of many leaders in the occupational therapy field.

\section{Leadership Theory}

The correlation between strong leadership and organizational success is continuously recognized. Various theories about leadership have been proposed over the years, affecting how individuals approach the subject (Fleming-Castaldy \& Patro, 2012). Until the 1940s, emphasis on leadership focused on trait theories and the "great man" theory (Ledlow \& Stephens, 2008). Trait theory assumes that specific individuals are destined to become leaders and that these individuals possess certain traits or attributes that result in them securing leadership roles (Ledlow \& Stephens, 2008). Acknowledgment that leadership and leading could be a learned skill came about in the 1940s with acceptance of the behavioral theory, which focused on determining particular behaviors or styles leaders used to cause others to follow them (Ledlow \& Stephens, 2008). The situational phase of leadership theory started to gain awareness in 1970 and continues to drive leadership theory today, suggesting that successful leaders choose the appropriate leadership style after assessing the situation to make the most significant positive impact on individuals and organizations (Ledlow \& Stephens, 2008). Al-Sawai (2013) discusses an emerging theory based on supportive leadership, which emphasizes the importance of building relationships with employees to increase the likelihood that they will be positively influenced and motived to work towards a common goal. Due to the inherent complexity of the health care system, we can assume that leaders who use the situational leadership theory 
alongside the supportive leadership theory can inspire and develop their team members to achieve individual and organizational aims (Truskowski, 2017).

\section{Leadership in Occupational Therapy}

\section{Problem Areas}

Since the first entry-level doctorate program in 1998, the Accreditation Council for Occupational Therapy Education (ACOTE) has periodically reviewed the profession's views on the role of the entry-level doctorate in the profession (ACOTE, 2018). However, it was not until 2013 the review took on higher intensity after the Council received the AOTA Future of Occupational Therapy Education Ad Hoc Committee Report recommending the move of the entry-point to a doctoral level. The members of the Council spent four years carefully reviewing and debating the issue to come to a conclusion that would provide the most significant benefit to both the profession and the recipients of service provided by the graduates from the academic programs. ACOTE's mandate was released in August 2017, requiring the entry-point for an occupational therapy degree to be at the doctoral level by July 1, 2027. One year later, ACOTE rescinded the mandate for the single point of entry. This debate has been ongoing for many years and continues to be the center of debate within the profession (ACOTE, 2018).

Occupational therapists have the potential to guide the profession forward by becoming influential leaders. However, when compared to other professions, occupational therapy lacks leaders within the healthcare field (Fleming-Castaldy and Patro, 2012). The current entry-level MOT curriculum and fieldwork components lack in the areas that educate students on leadership, which could be a contributing factor to the lack of leads within the occupational therapy field (AOTA, 2018). Although AOTA has taken steps to begin changing the curriculum through the 
development of the entry-level doctorate program, there is no mandate in place requiring all occupational therapy programs to transition to the entry-level doctorate level (AOTA, 2018).

The AOTA is demonstrating a press within occupational therapy for clinicians to take on leadership roles, with an emphasis on leadership in Vision 2025 (AOTA, 2017). FlemingCastaldy \& Patro (2012) point out the lack of literature characterizing the important qualities occupational therapists should possess in order to be successful within leadership roles. Also, there is a lack of literature on entry-level clinicians' role in leadership, which could be because entry-level clinicians do not demonstrate leadership within the field (Braverman, 2016). Information about essential qualities needed for successful leadership will help provide entrylevel practitioners with the knowledge about potential steps they can take to become leaders in the field.

\section{Leadership versus Management}

Leadership and management are two terms that are often used interchangeably in the healthcare field; however, it is essential to note that these two terms differ. According to Fleming-Castaldy \& Patro (2012), managers are those who are concerned with maintenance, while leaders are continually encouraging the facilitation of change. Unlike leaders, managers tend to control and direct relying on structure, strategy, and systems to ensure the maintenance of the current organization (Phipps, 2015). Leaders are committed to developing others as well as their field of expertise in order to move organizations forward. Leaders are continually collaborating with others, empowering others to develop innovative approaches, and are open to challenges and critiques (Fleming-Castaldy \& Patro). Leaders encourage and empower others through collaboration and shared decision-making in order to create sustainable changes that enable organizational success (Fleming-Castaldy \& Patro, 2012). It is not to be assumed that 
managers cannot be leaders because the combination of leadership and management is crucial to organizational success. However, the methods used to manage individuals and organizations are what set apart those who are leaders (Phipps, 2015). An individual can be a leader, even if he or she does not have a job title or description of managerial or administrative responsibilities (Phipps, 2015). An entry-level clinician can serve as a leader by collaborating with colleagues, coming up with innovative treatment ideas, being aware of current legislation, or taking the initiative to develop a program at a facility to fulfill a need that is not being addressed.

\section{Informal Leadership}

A common misconception in leadership is that one must hold a formal title with a job description involving administration or management properties to be considered a leader. It is often assumed that a leader is someone who has a formal title and job description with managerial and administrative responsibilities (Heard \& Scott, 2018). However, if this were the case, it would be nearly impossible for new-graduates or entry-level clinicians to demonstrate leadership. Heard \& Scott (2018) identify how informal leaders play a role in the field of occupational therapy by "mentoring students and peers, coaching team members, and sharing knowledge through scholarship and teaching" (p. 11). Felming-Castaldy \& Patro (2012) pointed out that leaders empower individuals. Heard \& Scott (2018) discuss how informal leaders do the same; they are the "go-to" staff and empower their colleagues through collaborative efforts in solving problems, being "the voices of reason, and the shoulders to cry on" (p. 9).

\section{Role of Entry-Level Clinicians}

Previously stated, new graduates or entry-level clinicians can demonstrate leadership as occupational therapists in the healthcare field. Entry-level clinicians generally do not see the importance of leadership because they are only concerned with patient care issues and 
transitioning into their new role as a clinician (Braverman, 2016). We can assume that the lack of literature on entry-level clinicians in leadership roles is because the majority of entry-level clinicians do not demonstrate a leadership role in the field. The Accreditation Council for Occupational Therapy Education (ACOTE) rescinded a previous mandate, requiring all entrylevel occupational therapy programs to transition to the entry-level doctorate. However, ACOTE is continuing to support and advocate for this transition (AOTA, 2018). Smallfield, Flanigan, \& Sherman (2019) conducted a quantitative study to compare the professional outcomes of the entry-level Master of Science of Occupational Therapy (MSOT) and the entry-level doctorate of occupational therapy (OTD). They found that OTD graduates were significantly more likely to hold at least one leadership position (Smallfield, Flanigan, \& Sherman, 2019). AOTA has adopted Vision 2025, which builds on the work of the Centennial Vision (AOTA, 2007) to guide the profession forward, with a strong emphasis on leaders (AOTA, 2017). AOTA wants entrylevel clinicians to become leaders, "envision[ing] that occupational therapy is a powerful, widely recognized, science-driven, evidence-based profession with a globally connected and diverse workforce meeting society’s occupational needs" (AOTA, 2007, p. 613).

\section{Qualities of a Leader in Healthcare}

Oliver (2006) discusses the vital role leadership plays in the success of any organization. A leader cannot lead or use their authority to effect change without the recognition and support of their title and authority by the team or individuals. The following seven qualities are essential for leaders in healthcare to demonstrate if they seek to provoke change within an organization: the ability to work independently; skills of an effective collaborator; capable of developing high trust relationships based on ethical standards; self-confidence tempered with humility; respect the process of change; and be able to work across business functions and units (Oliver, 2006). 
According to Al-Haddad (2003) strong leadership within healthcare is vital because "the complexity of the healthcare system requires the qualities of a good leader who can link the world of management to the world of medical/clinical practice, while understanding people's needs and accommodating and developing the broad array of health services needed by them" ( $p$. 1). In order to attain a high level of leadership and success, motivation, shared vision, excellent communication, proper time management, and a situational approach to leadership are the most important and essential qualities (Al-Haddad, 2003). Cain (2005) also points out five practices of exemplary leadership, which include a leader who models the way, inspires a shared vision, challenges the process, enables others to act, and encourages the heart. We can assume that the most important and essential qualities demonstrated by an active leader in health care involves supporting and building up individuals or team members.

\section{Theory}

\section{Situational Leadership Theory}

Flexibility is a critical factor in being an active leader in the healthcare industry, thus relating to the situational leadership theory. Ostrove (2015) discusses the importance of supervisor flexibility because "employees tend to share aspects of more than one level of learning” (p. 1). For instance, take into consideration the individuals within an entry-level occupational therapy program. Each individual has his or her way of studying or learning new material. One person may rely on listening to someone discuss the information, while another individual may prefer to read or write down the information. The situational leadership theory uses a similar concept. Situational leadership involves a clinician evaluating the needs of the individuals in their team and adjusting their managerial style to meet the learning needs (Ledlow \& Stephens, 2018). 
The situational leadership theory makes responding to change as a leader easy because of the flexible nature of the leader. According to Heard \& Scott (2018), "leaders prepare organizations for change and help them cope with the related challenges" (p. 1). The situational leadership theory can be applied within the healthcare field to respond to change by adapting to the needs of the facility, patients, or colleagues as needed. As Ostrove (2015) reports, when using this model the leader has "the ability to identify an employees learning needs, the ability to adjust leadership style to address those needs, and the ability to engage the employee in a partnership to develop the skills he or she needs" (p. 1). Responding to change is not difficult when using the situational leadership model because not everyone or everything is the same. Thus requiring the leader to be able to change and adapt to ensure patients, as well as other professionals, are getting what they need in order to fulfill their roles successfully.

\section{Ecology of Human Performance (EHP)}

The Ecology of Human Performance (EHP) model will serve as the theoretical framework for this capstone. Occupational therapist, Winnie Dunn, and colleagues founded the EHP model in 1994 at the University of Kansas Medical Center (Cole \& Tufano, 2008). This model was developed to help bridge the gap within occupational therapy theory and practice. Context had not yet been considered as an essential factor in occupational performance (Dunn, Brown, McGuigan, 1994). Dunn, Brown, \& McGuigan (1994) identify the foundation of the EHP model, which is that the interaction between a person and their environment affects their behavior and performance and that contextual influences must be considered to understand a person's performance within the environment. There are four primary constructs of EHP: person, task, context, and person-context-task interaction (Cole \& Tufano, 2008). The 
transactional process through which the person, context, and task performance affect each other is what leads to human performance (Cole \& Tufano, 2008).

The four constructs of the EHP model allow it to transfer to a variety of settings with an interdisciplinary focus. Truskowski (2017) states that the "interdisciplinary nature of the EHP makes it an appropriate model from which to study leadership due to leadership being a part of virtually every profession" (p 16). From the EHP perspective, the person is an individual with his configuration of abilities, experiences, sensorimotor, cognitive, and psychosocial needs (Cole \& Tufano, 2008). When applying EHP's description of the person to leadership, the leader must assess the skills, abilities, traits, strengths, and weaknesses of each member of their team. Ostrove (2015) discusses the importance of the situational leadership style because each person has his or her learning style. As a leader, it is essential to be able to identify the needs of the individuals who make up the team and adjust the leadership style to meet the learning needs to create a positive and successful work environment (Ostrove, 2015). According to the EHP model, performance can only be understood via one's context, which is affected by temporal and environmental aspects (Cole \& Tufano, 2008). Truskowski (2017) identifies contextual factors that affect leadership decision-making, such as "specific deadlines, the physical space allotted to a task, or whether a particular situation requires an individual or team approach." Instead of occupations, Dunn, Brown, \& McGuigan (1994) use the term tasks to identify a specific set of behaviors necessary to accomplish a particular goal. Leadership related to task factors can include addressing individual or group behaviors, as well as outcomes that will be required to complete a particular task (Truskowski, 2017).

\section{Conclusion}


The evidence found in the literature indicated a need for more occupational therapists to demonstrate leadership within the profession to advance the profession as a whole. Entry-level clinicians have the drive and determination to produce change; however, lack of knowledge and education on how to become a leader is hindering the potential these clinicians have to become the influential leaders this profession needs. Leadership can be demonstrated by anyone in the field of occupational therapy, regardless of titles or job descriptions (Heard \& Scott, 2018). Program development is a way to demonstrate leadership because it involves performing a needs assessment to determine what an organization is missing, collaborating with therapists and managers, producing a vision, and bringing that vision to life. Bridging the gap by providing knowledge about leadership and opportunities for students or entry-level clinicians to demonstrate leadership will increase leaders in the profession, thus advancing the field of occupational therapy. Using the EHP model and situational leadership theory as a guide and taking into consideration the importance of leadership within the field of occupational therapy, this capstone project has the opportunity to serve as an example of how an occupational therapy student can demonstrate leadership within the profession.

\section{Chapter III: Project Description}

\section{Introduction}

This capstone project aimed to learn about leadership through expertise and experience. The project consisted of two portions. The first portion consisted of reviewing the literature and interviewing several occupational therapists that have a leadership role in the healthcare industry to gain insight into leadership qualities. The interviews took place during the first four weeks of the capstone experience during the initial stages of program development. The second potion included being at a facility, Advent Therapy in Richmond Hill, G.A., for fourteen weeks to 
observe and learn about current programs, and with the guidance of the therapists and management at the facility, develop and implement a program that would be beneficial to the client population. The purpose of this section is to describe the planned capstone project and process or methods that were employed to execute this project. Additionally, this section presents a realistic timeline to achieve stated capstone objectives.

\section{Purpose Statement}

The purpose of this capstone project was to demonstrate leadership as an entry-level doctorate of occupational therapy students through program development and implementation, utilizing the leadership qualities identified through interviewing successful occupational therapy leaders. Learning about leadership and having the opportunity to participate in a leadership role as a student or as an entry-level clinician can form influential leaders that will shape the future of the profession (Smallfield, Flanigan, \& Sherman, 2019).

\section{Rationale}

Life transitions, such as attending school or getting a new job, can be stressful, especially for entry-level occupational therapists that are transitioning into a new role from student to professional. These former students are attempting to prove themselves as confident, competent clinicians surrounded by other professionals who may have years of experience in the field. The literature shows that many occupational therapy students and new graduates do not demonstrate leadership within the field because they are only concerned with their new role as a clinician (Braverman, 2016). It can be assumed that entry-level clinicians have the drive to create change within the field of occupational therapy, but are unaware of the necessary steps to take to demonstrate leadership through advocating for the profession and provoking change. FlemingCastaldy \& Patro (2012) report that in "a survey of healthcare practitioners regarding 36 
managerial skills and competencies" expected for new graduates in their field to possess revealed the occupational therapists placed a greater emphasis on "the need for leadership skills than the other medical professionals surveyed" (p. 190-191). This capstone will help to exemplify the essential qualities of occupational therapists that demonstrate leadership well and provide the potential steps entry-level practitioners can take to become leaders within the field without having to hold a formal title.

\section{Significance}

AOTA has demonstrated a push and emphasized leadership within the field of OT with the development of the entry-level doctorate program, in addition to AOTA's Vision 2025 (AOTA, 2017) to help guide the future of the profession (Fleming-Castaldy \& Patro, 2012). However, the current entry point to becoming a licensed occupational therapist is a master's degree, where the curriculum lacks education on leadership and leadership roles within the field (AOTA, 2018). The occupational therapy profession lags behind other rehabilitation professions, which can be contributed to the lack of occupational therapists contributing to leadership within the field. Entry-level OTD students, in addition to entry-level clinicians, have the education and potential to become influential leaders within the field and progress the profession forward. Increasing the number of occupational therapy leaders is vital to the field to defend our patients' rights to services, ensure clinicians are getting what they deserve regarding finances, health and well-being, and advocate for the profession.

\section{Process/Methods}

\section{Participants}

Occupational therapists with various leadership roles were recruited and interviewed for the first portion of this project. Participants in the interviews were identified through Mary 
Shotwell, Ph.D., OT/L, FAOTA, professor and Interim Program Director of MOT/OTD Programs at the University of St. Augustine for Health Sciences. They received an invitation to participate letter via e-mail. Four OTs responded to the email and indicated their willingness to participate in interviews. There were no participation restrictions placed on age, gender, geographical location, or years of OT leadership or practice experience. All participants being interviewed were required to be demonstrating leadership within the field of occupational therapy actively.

The participants included in the second portion of this project were identified through current patients receiving occupational therapy services at Advent Therapy. Thirteen caregivers of children with special needs were given a survey to determine if they were interested in participating in a caregiver education program at the facility. A total of eight surveys were returned with these caregivers showing interest in participating in the program. There was no participation restrictions placed on age, gender, or years serving as a caregiver to a child with special needs. All participants in the caregiver education program were required to currently be caring for a child with special needs, who was receiving services at Advent Therapy.

\section{Setting}

The first portion of this project was carried out via Skype interviews or over the phone, interviewing four occupational therapy leaders to gain insight into leadership qualities that make them useful and efficient leaders. The second portion of this project was carried out at a private practice outpatient lifespan clinic, Advent Therapy, in Richmond Hill, G.A.. The Advent Therapy team consists of four physical therapists, one physical therapy assistant, three occupational therapists, three speech-language pathologists, a patient coordinator, and a clinic coordinator. This clinic is a rehabilitation facility that offers a variety of services, including 
physical therapy, occupational therapy, speech therapy, sports conditioning, and vestibular rehabilitation. Patients range from all ages, newborns to elderly adults; however, the clinic sees a large portion of patients who fall into the pediatric population.

\section{Development Process}

DoD and AHRQ (2012) developed an evidence-based teamwork program, TeamSTEPPS 2.0, designed to optimize patient outcomes by improving communication and teamwork skills among healthcare professionals. The steps defined within the TeamSTEPPS 2.0 program were modified and used as a basis for program development within this capstone. Step one of the development process of the program began with an informal needs assessment through collaboration with the therapists and management at Advent Therapy during routine daily operations to determine the greatest need of the client population at the facility, thus determining the type of program. Step two included defining the aims of the program, including what the goals of the program to be achieved were, who would be involved, and when and where the improvements would occur. Step three of this process consisted of developing educational content and handouts about particular topics through research and collaboration with therapists at the facility that would address the targeted problem and achieve the stated aims. Step four entailed developing a plan and tool to be used to test the effectiveness of the program and determine if the stated aims were achieved. Step five was comprised of developing an implementation plan for the program being developed, including the duration of the program in weeks, how many days a week sessions would be offered, what time of day the session would be given, and how long the sessions would last. Step six was used to develop a plan for continuous process improvement for the program being developed, including "plans for ongoing assessment of the effectiveness of the [program], for sustainment of positive changes, and for identification 
of opportunities for further improvements" (HHS, 2012 p. 18). Developing a communication plan with the therapists and management at the facility was step seven. A communication plan was developed to promote the maintenance of the program and to spread positive changes. The last step, step 8, was reviewing the developmental process and action plan with key personnel, including, but not limited to, at least two occupational therapists and the director at the facility the program was being developed for (DoD \& AHRQ, 2012).

\section{Implementation Process}

Once assessment and planning were completed, the next step was implementing the strategies and components that made up the developed program at the facility. The focus of the capstone project was on parent/caregiver education regarding developmental milestones for parents/caregivers of children currently receiving services at Advent Therapy. The program took place online and was a total of 6-weeks with a video released on the facility's website at the beginning of each week. The six videos on caregiver education regarding developmental milestones were as follows: 1) Introduction Video-About Occupational Therapy; 2) ADLsdressing, toileting, bathing \& grooming, and eating \& drinking; 3) Fine Motor Skills; 4) Prewriting strokes/Handwriting; 5) Social \& Emotional Development; and 6) Understanding \& Thinking (cognitive). Each video included the developmental milestones for the above topics from infant to school-aged (newborn-6 years old), in addition to red flags and recommendations on certain toys and activities parents/caregivers can use at home to help their child if they notice they are behind. Participation included filling out a short questionnaire prior to participation, watching one seven-to-nine-minute video a week for six weeks, and filling out another short questionnaire after watching all of the videos. The goal of the questionnaire was to determine if the education provided was effective. The first week included the administration of a 
caregiver/parent participation agreement form and the pre-program implementation questionnaire prior to watching video one. After each video was released, the OTD student, at least one occupational therapist, and the director of the facility discussed the strengths and weaknesses of the particular video to ensure the ongoing quality of the program throughout the six weeks (Toseland, 2004).

\section{Evaluation Component.}

The program was evaluated to examine the effectiveness, using a pre- and post-program implementation questionnaire. Twenty multiple-choice questions were used to determine parents/caregivers knowledge on developmental milestones (Case-Smith \& O'Brien, J.C., 2015; CDC, 2019; Children's Therapy \& Family Resource Centre, 2011; \& Ertem, Atay, Dogan, Bayhan, Cok, Ozbas, Haznedaroglu, \& Isikli, 2007). This evaluation design consisted of four steps: 1) gathering data before the implementation of the program, 2) implementing the developed program, 3) gathered the same data after implementation of the program, and 4) compare the results of the pre-program implementation data to the post-program implementation data (DoD \& AHRQ, 2012). The findings from the pre- and post-program implementation questionnaires were used to assess the program's impact and determine any adjustments that needed to be made, such as content or delivery methods of content.

\section{Alignment with Objectives}

As previously stated, the purpose of this capstone project was to demonstrate leadership through program development and implementation, while exhibiting essential leadership qualities identified through interviews with current leaders to do so. This capstone experience took place at Advent Therapy, a lifespan clinic. The two learning objectives of this capstone focused on knowledge about the role of leadership within the field of occupational therapy and 
the qualities effective leaders possess. These objectives were met through a review of the literature and after the completion of the interviews. The four outcome objectives involved program development, implementation, and evaluation. The methods outlined above discussed the participants taking part in the interviews, as well as the participants taking part in the developed program. Furthermore, the methods section outlined how the process of program development, implementation, and evaluation looked for this project in its entirety. By accomplishing the two learning objectives, in addition to carrying out the methods outlined above, the outcome objectives were met by the end of the fourteen weeks.

\section{Conceptual Framework}

The CDC (2018) describes the Logic Model in program development, as a course of action used to aid organizations in achieving the goals and outcomes of a particular program to ensure lasting change. The components of the logic model include inputs, outputs, outcomes, assumptions, and external factors (ACF, 2012). The purpose of this section is to describe the Logic Model in detail as it related to program development and this capstone.

Inputs are part of the planning elements that describe the resources available or needed to support the program (ACF, 2012). The inputs for the caregiver education program being developed included, the staff at Advent Therapy in Richmond Hill, G.A. staff; financial resources, such as ink and paper for educational handouts, surveys for evaluation, and drinks/snacks for participants; space to implement the developed program; and materials, including ink, paper, pens, computer, projector, tables, and chairs.

Outputs include the aspects that describe the actual program and are divided into activities and participation (ACF, 2012). The activity outputs were as followed: technical assistance to Advent Therapy about demonstrating leadership through program development and 
implementation; pre-program implementation survey given to parents/caregivers of children with special needs; a free 6-week educational program on caring for children with special needs using direct and indirect methods covering a different topic each week; and a post-program implementation survey given to parents/caregivers of children with special needs. The participants expected to benefit from this program included the therapists employed at Advent Therapy and the parents/caregivers of children with special needs who receive services through Advent Therapy.

Outcomes are defined in the Logic Model as the goals the program is hoping to achieve (ACF, 2012). They include short-term, intermediated, and long-term outcomes (ACF, 2012). The three outcomes the therapists were expected to achieve from this program were gaining program development and implementation skills, becoming skilled in program development, implementation, and evaluation, and gaining leadership qualities and skills through the process of program development. The outcomes associated with the parents/caregivers of children with special needs were gaining an increased understanding about developmental milestones and applying the knowledge gained to their everyday routine, thus decreasing parent/caregiver stress by providing the knowledge they needed to ensure future success for their children in areas of self-care, play, social functioning, and education participation. The long-term outcome hopes to improve physical and mental health statuses, family functioning, and social participation, thus increasing the overall quality of life (Lai, \& Oei, 2014).

In addition to the inputs, outputs, and outcomes, it is essential to evaluate the indirect influences that could potentially affect the implementation of the developed program. Thus, the assumptions and external factors that may influence the implementation of the program or desired outcomes must be considered (CDC, 2018). Assumptions were as follows: resources are 
available and adequate; curriculum on caring for a children with special needs can be developed and delivered effectively; the therapists at Advent Therapy are willing and able to contribute; knowledge change leads to behavior change; and therapists and staff with expertise in pediatric developmental milestones were willing and able to assist with program development and implementation. The external factors included team attitude, management support, organizational support, and the establishment of a new program at Advent Therapy in Richmond Hill, G.A., to address the lack of knowledge and education parents/caregivers had on developmental milestones.

\section{Timeline}

\section{Review of the Literature}

The review of the literature is an ongoing process and, therefore, will continue throughout this project. The occupational therapist's role in leadership was reviewed before the start of this capstone experience. Throughout the 14-weeks, the student continued referring to literature regarding leadership. Also, the student reviewed literature on the subjects of the program being developed to provide the most reliable and up-to-date information about developmental milestones.

\section{Interviews}

Interviews with leaders in the field of occupational therapy were conducted via Skype or over the phone throughout weeks five though seven. The purposes of these interviews were to gain insight into essential leadership qualities effective leaders in occupational therapy possess. The student used these leadership qualities throughout the capstone experience to demonstrate leadership through program development, implementation, and evaluation.

\section{Program Development}


Week one at the facility began the process of program development, which is outlined above in the Process/Methods section of this paper. Week one focused on collaboration with the director of the facility, Advent Therapy, and the OTs employed at the clinic to discuss the overall needs of the facility. In addition to collaboration, an informal needs assessment was conducted through interviews with the management and staff at Advent Therapy and the parents/caregivers of children receiving OT services. The program being developed was established in week three, and the remainder of the developmental process occurred through week eight, which is outlined above.

\section{Program Implementation.}

Implementation of the developed program at the facility began Week eight and continued through Week 14, occurring over six weeks. The program took place online and was a total of six-weeks with a video released on the facility's website at the beginning of each week. The six videos on caregiver education regarding developmental milestones are as follows: 1. Introduction Video: About Occupational Therapy; 2. ADLs: dressing, toileting, bathing \& grooming, and eating \& drinking; 3. Fine Motor Skills; 4. Prewriting strokes/Handwriting; 5. Social \& Emotional Development; and 6. Understanding \& Thinking (cognitive). At the end of each week, the student collaborated with at least one occupational therapist and the director of the facility to discuss each session's strengths and weaknesses to make adjustments as needed to ensure and maintain the quality of the program.

\section{Program Evaluation}

Evaluation of the program began at the beginning of the implementation process. Before the first session officially begun, in week eight, participants filled out a pre-program implementation questionnaire as part of the evaluation component. At the conclusion of the last 
session, in week 14, participants filled out a similar questionnaire, serving as the post-program implementation survey. Week 14 included comparing the responses between the two questionnaires and determining the effectiveness of the program. In addition, the last week consisted of concluding the capstone experience by making recommendations for future programs being developed and implemented at the facility based on the evaluation from the caregiver education program.

\section{Envisioned Next Steps}

It can be assumed that the field of occupational therapy will continue to fall behind other healthcare professions, specifically rehabilitation professions, if clinicians do not take the initiative and become leaders. Influential leaders within the field are essential to push the profession forward to bring about change by translating ideas into reality (Truskowski, 2017). The goal of this capstone was to demonstrate leadership through program development and implementation by gaining insight into shared the shared qualities of occupational therapists that are influential leaders within the profession. It is expected that after the completion of this project, entry-level practitioners will have access to information about leadership and the steps they can take to become leaders in the field. Long-term, it is desired that this project will bring awareness about the importance of leadership to occupational therapists, specifically to new graduates, and contribute to an increase in leaders within the OT profession.

\section{Conclusion}

The purpose of this section was to outline how the student achieved the purpose of this capstone project, which was to demonstrate leadership through program development using essential qualities identified in interviews with successful occupational therapy leaders. To achieve the purpose, this project was divided into two parts: 1) interviews and 2) program 
development. To determine essential leadership qualities, the student identified and interviewed four successful occupational therapy leaders. To establish essential leadership qualities, the student reviewed the interviews upon completion for common themes. Once essential leadership qualities were identified, the student was able to use them to demonstrate leadership by developing, implementing, and evaluating a program at Advent Therapy in Richmond Hill, G.A. Through the use of TeamSTEPPS 2.0 (DoD \& AHRQ, 2012) and the Logic Model (CDC, 2018), the student was able to effectively complete the in-depth process of program development. The development of a timeline gave the student something to refer to and allowed this capstone project to be carried out in its entirety. The next section of this paper discusses and analyzes the results of the interviews and program development process.

\section{Chapter IV: Results and Analysis}

\section{Project}

The purpose of this capstone project was to demonstrate leadership through program development, implementation, and evaluation using essential qualities identified through interviews with current occupational therapy leaders from various backgrounds. To demonstrate leadership, the student learned about leadership through the literature, conducted interviews with successful leaders within the field of occupational therapy, and observed healthcare processionals that have a leadership role in the industry. The student was able to demonstrate leadership using the essential leadership qualities found through the literature, interviews, and observations through developing, implementing, and evaluating a program for a lifespan clinic, Advent Therapy, in Richmond Hill, G.A.

\section{Interviews}


Four individuals who have demonstrated leadership and are currently demonstrating leadership within the field of occupational therapy were interviewed for the first portion of this capstone project. Participants in the interviews were identified through Mary Shotwell, Ph.D., OT/L, FAOTA, professor and Interim Program Director of MOT/OTD Programs at the University of St. Augustine for Health Sciences. The backgrounds of these individuals are briefly discussed later in this chapter. Each interview took place over the phone or via Zoom and varied in duration from thirty minutes to one hour.

\section{Program Development Process}

The second portion of this capstone was carried out at a lifespan clinic, Advent Therapy, in Richmond Hill, G.A. TeamSTEPPS 2.0 is an evidence-based teamwork program developed by DoD and AHRQ (2012), designed to optimize patient outcomes by improving communication and teamwork skills among healthcare professionals. The steps defined within the TeamSTEPPS 2.0 program were modified and used as a basis for program development for this capstone project. To begin the program development process, an informal needs assessment was completed by collaborating with the therapists and management at Advent Therapy during routine daily operations to determine the greatest need of the client population at the facility. In addition, the student sat in multiple occupational therapy sessions throughout the first four weeks and was able to observe and talk with clients and parents/caregivers. After meeting with the therapists and management at the facility and observing and conversing with parents/caregivers, it was apparent that parents/caregivers at this facility lacked knowledge regarding developmental milestones.

Once the type of program being developed was determined, the student defined the aims of the program, including what the goals of the program to be achieved were, who would be 
involved, and when and where the improvements would occur. The goal of the program was to increase parent/caregiver education on developmental milestones in order to increase child success in daily activities, including activities of daily living, play, and education participation. Next, the student spent time going through the literature, online websites, and textbooks to gather educational content about developmental milestones. With the content gathered, the student was able to put six videos on developmental milestones together with the following topics: 1) Introduction-About Pediatric Occupational Therapy; 2) Activities of Daily Living (ADLs)dressing, toileting, bathing and grooming, and eating and drinking; 3) Fine Motor Skills; 4) Prewriting Strokes/Handwriting; 5) Social and Emotional Development; and 6) Understand and Thinking.

The next step entailed developing a plan and tool that was used to determine if the aims of the program were achieved. The program was evaluated to examine the effectiveness, using a pre- and post-program implementation questionnaire. Twenty multiple-choice questions were used to determine parents/caregivers knowledge on developmental milestones (Case-Smith \& O’Brien, J.C., 2015; CDC, 2019; Children's Therapy \& Family Resource Centre, 2011; \& Ertem, Atay, Dogan, Bayhan, Cok, Ozbas, Haznedaroglu, \& Isikli, 2007). An implementation plan was developed next.

To increase the amount of participants, the student collaborated with the therapists and management at the facility to determine an online program would be best to fit the needs of the parents/caregivers and increase the number of participants. The program provided education on developmental milestones in children from newborns to six-years old and took place over a sixweek period, with one seven-to-nine minute video being released each week. The parents/caregivers were provided a link to a YouTube video each week and were given the 
opportunity to watch the video at a time that was convenient for them. The student's site supervisor and OTD coordinator approved each video prior to it being viewed by parents/caregivers. A communication plan was developed and the developmental process and action plan was reviewed with the therapists and management at the facility prior to implementation.

\section{Program Implementation}

The focus of the capstone project was on parent/caregiver education regarding developmental milestones for parents/caregivers of children currently receiving services at Advent Therapy. The program took place online and was a total of six-weeks. The parents were provided with a YouTube link at the beginning of each week and were able to watch the video at anytime they chose. Each video included the developmental milestones for the pre-determined topics discussed above from infant to school-aged (newborn-6 years old), in addition to red flags and recommendations on certain toys and activities parents/caregivers can use at home to help their child if they notice they are behind. Participation included filling out a twenty question multiple choice questionnaire, watching one seven-to-nine-minute video a week for six weeks, and filling out a similar twenty question multiple choice questionnaire after watching all of the videos. The student met with 18 parents/caregivers and they received a caregiver/parent participation agreement form. The student received eight forms back, and those parents were given the pre-program implementation questionnaire at the beginning of Week 1, prior to watching the first video. To ensure the ongoing quality of the program throughout the six weeks the OTD student, at least one occupational therapist, and the director of the facility discussed the strengths and weaknesses of the particular video (Toseland, 2004).

\section{Measurement of Effectiveness}


The program developer was able to determine effectiveness thorough program evaluation utilizing a pre-and post-program implementation questionnaire (Appendix A and B). The program was evaluated to determine how effective the program was at providing education to parents/caregivers on developmental milestones. Four steps were used to measure the effectiveness of the program: 1) data was gathered before the implementation of the program; 2) the program was implemented; 3) the same data was gathered after the implementation of the program; and 4) the pre-program implementation data were compared to the post-program implementation data (DoD \& AHRQ, 2012). Twenty multiple-choice questions were used to determine parents/caregivers knowledge on developmental milestones prior to program implementation and a similar twenty-multiple choice questions were used to determine the same information at the completion of program implementation (Case-Smith \& O'Brien, J.C., 2015; CDC, 2019; Children's Therapy \& Family Resource Centre, 2011; \& Ertem, Atay, Dogan, Bayhan, Cok, Ozbas, Haznedaroglu, \& Isikli, 2007). The Caregiver Knowledge of Child Development Inventory, developed by Ertem, Atay, Dogan, Bayhan, Cok, Ozbas, Haznedaroglu, \& Isikli (2007), was adapted and modified to create the pre-and post-program implementation questionnaires. Additional resources were referred to when creating the questionnaires, including the Centers for Disease Control and Prevention Milestone Checklist (CDC, 2019) and CaseSmith and O’Brien (2015) tables on the "Development of Play Occupations."

Eight pre-program implementation questionnaires were returned with a mean score of $43.75 \%$ and four post-program implementation surveys were returned with an average score of $78.75 \%$ (Refer to Table 1). Although only fifty percent of the participants returned the postprogram implementation questionnaire, it can be assumed that the program was effective in increasing parents/caregivers knowledge on developmental milestones. The four 
parents/caregivers who returned the post-program implementation questionnaire demonstrated an increase in the number of questions answered correctly, thus showing an increase in knowledge regarding developmental milestones. In addition to the survey results, more than half of the participants gave positive comments about the educational videos on developmental milestones, indicating that it provided good, useful information. Participant 3 stated, "I wish I could have watched these videos while my first child was an infant. The information is very helpful." Participant 2 reported that she would be utilizing these videos in the future when she decides to have more children. We can assume the program was effective in providing education on developmental milestones to parents/caregivers of children with special needs from newborns to six years of age.

Table 1. Pre-and Post-Program Questionnaire Results

\begin{tabular}{|l|c|c|}
\hline Participants & $\begin{array}{c}\text { Pre-Program Implementation } \\
\text { Questionnaire }\end{array}$ & Post-Program Implementation \\
\hline 1 & $11 / 20(55 \%)$ & $16 / 20(80 \%)$ \\
\hline 2 & $7 / 20(35 \%)$ & $13 / 20(75 \%)$ \\
\hline 3 & $8 / 20(40 \%)$ & $14 / 20(70 \%)$ \\
\hline 4 & $9 / 20(45 \%)$ & N/A \\
\hline 5 & $9 / 20(45 \%)$ & N/A \\
\hline 6 & $10 / 20(50 \%)$ & N/A \\
\hline 7 & $12 / 20(60 \%)$ & N/A \\
\hline 8 & $5 / 20(25 \%)$ & $\mathbf{7 2 . 5 0 \%}$ \\
\hline Average Score & $\mathbf{4 3 . 7 5 \%}$ & \\
\hline
\end{tabular}




\section{Results/Discussion}

\section{Interviewees}

The four occupational therapy leaders interviewed for the first portion of this capstone project each had a variety of leadership roles and titles throughout their careers thus far. Interviewee one has spent the majority of her career working in outpatient rehabilitation, becoming a franchise owner of the outpatient clinic she was working for over ten years ago. She has held various formal leadership titles, currently being the highest ranking female in the company holding the title of Senior VP of Clinical Development over 775 clinics. Interviewee two held a formal leadership title of Motor Department Administrator for seventeen years within a school system before transitioning to becoming a professor at an accredited occupational therapy program. As a professor she was given the opportunity to demonstrate leadership again by transforming the pediatric curriculum and the faculty-based practice clinic at the university. Interviewee three has demonstrated leadership throughout her career focusing on assisted dog training. Some things she has done throughout her career include developing programs all over the world, teaching at Assisted Dog Training Association conventions, serving on ethic committees and boards, and being the first person to present on animal-assisted therapy at an AOTA conference and later writing an article that was published. Lastly, interviewee four has held formal leadership titles at a large hospital including Assistant Director of Occupational Therapy and Outreach Program Director, in addition to becoming a Fieldwork Coordinator at for an accredited OT program. She also has a background in program development.

\section{Themes from Interviews}


Interviewing leaders within the field of occupational therapy provided immense insight into the character traits and qualities that have made them effective and successful leaders throughout their careers.

The interviewer noted that each interviewee often took on many roles and projects at a time and never turned down opportunities to make a difference in the field of occupational therapy or in the lives of others. Interviewee two reported that there were times throughout her career where she has felt like she had taken on too much and needed to cut back, so she could make one project great instead of several adequate. Interviewee three stated, "Do not say no. Everything is an opportunity." We can assume that successful leaders tend to be relentless with their visions, never giving up or wanting to turn down an opportunity to make a difference and help others.

When it came to leading others, a common theme noted was the use of a facilitative leadership approach. Interviewee four stated, "to be an effective leader, it is imperative to understand facilitator leadership." According to Smith (2003), facilitative leadership emphasizes a shared responsibility for learning, empowering people, and encouraging a team effort while providing clear expectations. Interviewee two reported that she is "always seeing clients" and "never asks therapists to do what I am not doing." This quote reiterates the importance of shared responsibility when engaged in leadership. Interviewee one defined leadership as "an approach to achieving a vision that allows team members to express [their] own unique talents in [an] individualized way." When using a facilitative leadership approach it can be assumed that these leaders have the ability to effectively work with other people, demonstrating good communication and listening skills. 
Each interviewee had demonstrated leadership through program development at some point throughout their careers thus far. When asked about the connection between program development and leadership, interviewee two described how effective leaders are always looking for opportunities, seeing gaps, and identifying and prioritizing needs of a population, clinic, or community and using creative and innovative ways to get around any challenges or barriers. Often times, developing a program is an effective solution to a problem or need. Interviewee four reported that "through program development, leaders in occupational therapy have the opportunity to demonstrate real zeal or commitment to helping people have better lives." Program development is an in-depth process requiring good problem-solving skills and creativity.

At the conclusion of the interviews, it was clear that each interviewee possessed the following same six qualities: creativity, ability to work with people, good communication skills, good at listening to others, relentless with a vision, and efficient at problem-solving.

\section{Program Development, Implementation, and Evaluation}

The six essential qualities identified in the interviews with occupational therapists demonstrating leadership within the field were used to develop a parent/caregiver education program on developmental milestones, implement the program at Advent Therapy in Richmond Hill, G.A., and evaluate the program's effectiveness. While completing the in-depth program development process, the student had to demonstrate creativity and good problem solving skills to decide how to deliver the program in a way that would be the most effective and get the most participation. Throughout the development and implementation process, the student continuously worked through obstacles, such as scheduling and technical issues to meet deadlines and see the program through fruition. Demonstration of good communication and listening skills were 
required with the therapists and management at the facility to ensure the ongoing quality of the program. In addition, communication and listening skills were used to interact with parents/caregivers throughout the program implementation process to make sure there were no technical issues and to gain insight into parents/caregivers thoughts on the content and delivery methods.

\section{Limitations and Delimitations}

\section{Limitations}

One limitation of this capstone project was related to time constraints through program development, implementation, and evaluation. A total of fourteen weeks was given to carry out the capstone project in its entirety. The first few weeks consisted of interviews with occupational therapists that have leadership roles in the field to determine essential qualities occupational therapists possess to be successful leaders. Next, determination of the type of program that would provide the most benefit to the clientele was determined through an informal needs assessment and collaborating with the administration and therapists at Advent Therapy. The program was then developed within the last two weeks of capstone experience one and the first four weeks of capstone experience two and implemented throughout a six-week time frame. One week was given to evaluate the effectiveness and success of the program and to make suggestions for future programs. A second limitation of this capstone project includes only developing a program at one facility with one group of participants, decreasing the ability to generalize the effectiveness of the program. A third limitation of this project was the limited number of caregivers who participated in the developed program.

\section{Delimitations}


Delimitations of this capstone project included the type of program being developed and implemented at the facility. Based on a needs assessment and collaboration with the administrators and therapists at Advent Therapy in Richmond Hill, G.A., it was evident that a caregiver education program was most beneficial for the population at the facility.

\section{Chapter V: Summary}

AOTA has been placing importance on leadership, encouraging occupational therapists to aid in developing and growing the profession. It emphasized the importance of leadership to achieve the goals outlined in AOTA's Vision 2025 (AOTA, 2019). In addition, moving the entrypoint of the profession to an entry-level doctorate continues to be a discussion between the AOTA and ACOTE (AOTA, 2018). The current entry-level occupational therapy curriculum lacks education on leadership and opportunities for students to demonstrate leadership within the field (Smallfield, Flanigan, \& Sherman, 2019). Entry-level clinicians have the ability to produce change, but are not demonstrating leadership within the field (Braverman, 2016). We can assume that the lack of knowledge on leadership due to the current curriculum is hindering the potential these clinicians have to become the influential leaders this profession needs. Occupational therapy students and entry-level clinicians can demonstrate leadership within the profession without having titles or job descriptions that deal with leadership directly (Heard \& Scott, 2018). Through program development, a student or entry-level clinician can demonstrate leadership by finding gaps within a population, community, or organization and using creative and innovative ways to solve the problem. The more students and therapists within the profession taking the steps to become leaders within the field with help contribute to pushing the profession forward.

\section{Implications for Practice}


Entry-level clinicians, or new graduates, do not often demonstrate leadership within the field of occupational therapy. To increase knowledge about leadership and fulfill leadership roles, occupational therapy students would benefit from opportunities to learn about and demonstrate leadership. However, opportunities for learning are limited or unavailable with the current MOT curriculum and fieldwork components (Smallfield, Flanigan, \& Sherman, 2019).

This capstone project explored the role of leadership within the field of occupational therapy. Using the essential leadership qualities identified in interviews to develop, implement, and evaluate a program at an outpatient rehabilitation facility, provided an example of how occupational therapy students or entry-level clinicians can demonstrate leadership within the profession. Additionally, information about the steps occupational therapy students or entry-level clinicians can take to develop a program are thoroughly discussed. Determining the essential qualities that have made occupational therapy leaders successful in the past and present provided the student with insight into demonstrating leadership. As a student or entry-level clinician, there are multiple ways to demonstrate leadership without holding a formal title, such as through program development. Using the qualities identified through interviews, the student was able to successfully complete the program develop process in its entirety and provided a clinic with a resource to benefit their clients indefinitely.

\section{Future Considerations}

The findings from this capstone project indicate a need for further research involving leadership within the field of occupational therapy, specifically related to students or entry-level clinicians. Current literature on important leadership qualities held by successful occupational therapy leaders is limited. Future research could involve a true qualitative study on leadership qualities, involving a large sample size. Knowing the important qualities that successful 
occupational therapy leaders possess would provide insight into components of demonstrating leadership. Additionally, other studies could analyze the current MOT and OTD curriculum and make suggestions to increase the education on leadership and opportunities to demonstrate leadership.

\section{Conclusions}

Fleming-Castaldy and Patro (2012) discuss the importance the profession has placed on the development of leaders in occupational therapy with the AOTA's Centennial Vision. The organization has been advocating for more occupational therapists, specifically entry-level practitioners, to demonstrate leadership within the profession. Despite the press within occupational therapy for clinicians to take on leadership roles, there is a lack of literature on the role entry-level clinicians have in leadership. Braverman (2016) described how occupational therapy students or entry-level practitioners generally do not see the importance of leadership because they are only concerned with patient care issues. As a result, the majority of entry-level clinicians do not demonstrate a leadership role in the field (Braverman, 2016). In addition, the current entry-level MOT curriculum and fieldwork components lack in areas that educate students on leadership (Smallfield, Flanigan, \& Sherman, 2019). We can assume that absence of knowledge on leadership can lead to entry-level clinicians feeling intimidated and lacking autonomy and confidence. If not addressed, the lack of leaders in the field may lead to further declines in the occupational therapy profession, such as not being recognized as necessary providers in the healthcare system. This capstone project aimed to illustrate the attributes of occupational therapists in leadership and the potential steps entry-level practitioners can take to become leaders in the field. Learning about leadership, determining common qualities that effective occupational therapy leaders possess, and having the opportunity to participate in a 
leadership role as a student or entry-level clinician will help form influential leaders that have the potential to change the profession through leadership roles. 


\section{References}

Accreditation Council for Occupational Therapy Education [ACOTE]. (2018). ACOTE's update on entry-level education [PDF file]. Retrieved from https://www.aota.org/ /media/Corporate/Files/EducationCareers/Accredit/Announcement s/ACOTE-Update-on-Entry-Level-Education.pdf

Administration for Children and Families [ACF]. (2012). Logic model tip sheet [PDF file]. Retrieved from https://www.acf.hhs.gov/sites/default/files/fysb/prep-logic-model-ts.pdf

Al-Haddad, M. (2003). Leadership in Healthcare Management. Bahrain Medical Bulletin, 25(1), 1.

Al-Sawai, A. (2013). Leadership of healthcare professionals: Where do we stand?. Oman Medical Journal, 28(4), 285-287. https://doi.org/10.5001/omj.2013.79

American Occupational Therapy Association [AOTA]. (2007). AOTA's Centennial Vision and executive summary. American Journal of Occupational Therapy, 61, 613-614. https://doi.org/10.5014/ajot.61.6.613

American Occupational Therapy Association [AOTA]. (2016). AOTA Unveils Vision 2025. Retrieved from https://www.aota.org/AboutAOTA/viion-2025.aspx American Occupational Therapy Association [AOTA]. (2017, April 20). Celebrating AOTA's centennial: A historical look at 100 years of occupational therapy [Video file]. Retrieved from https://www.youtube.com/watch?v=DbCwf2CzGvw

American Occupational Therapy Association [AOTA]. (2017). Vision 2025. American Journal of Occupational Therapy, 71, 7103420010. https://doi.org/10.5014/ajot.2017.713002 
American Occupational Therapy Association [AOTA]. (2018). ACOTE 2027 Mandate update and timeline. Retrieved from https://www.aota.org/EducationCareers/Accreditation/acote-doctoral-mandate-2027.aspx

American Occupational Therapy Association [AOTA]. (2019). Medicaid. Retrieved from https://www.aota.org/Advocacy-Policy/Federal-Reg-Affairs/Pay/medicaid.aspx

Bopp, A. (2019). Medicare Home Health Flexibility Act introduced in house and senate. American Occupational Therapy Association [AOTA]. Retrieved from https://www.aota.org/Publications-News/ForTheMedia/PressReleases/2019/060719Medicare-Home-Health-Flexibility-Act.aspx

Braveman, B. (2016). Leading \& managing occupational therapy services: An evidence-based approach. Philadelphia, PA: FA Davis.

Brown, A.M. (2016). What is this thing called 'theory of change'?. Retrieved October 19, 2019 from https://usaidlearninglab.org/lab-notes/what-thing-called-theory-change

Brown, T., Crabtree, J. L., Mu, K., \& Wells, J. (2015). The next paradigm shift in occupational therapy education: The move to the entry-level clinical doctorate. American Journal of Occupational Therapy, 69, 1-6. https://doi.org/10.5014/ajot.2015.016527

Cain L.B. (2005). Essential qualities of an effective clinical leader. Dimensions of Critical Care Nursing, 24(1), 32-34. Retrieved from http://search.ebscohost.com/login.aspx?direct=true\&db=ccm\&AN=106621140\&site=eds -live

Case-Smith, J. \& O’Brien, J.C. (2015). Chapter 3: Development of childhood occupations. Occupational Therapy for Children and Adolescents ( $7^{\text {th }}$ ed., pp. 65-101). St. Louis, MO: Elsevier Mosby 
Centers for Disease Control and Prevention [CDC]. (2019). Milestone checklist [PDF file\}. Retrieved from https://www.cdc.gov/ncbddd/actearly/pdf/checklists/Checklists-withTips_Reader_508.pdf

Centers for Disease Control and Prevention [CDC]. (2018). Logic models. Retrieved October 27, 2019 from https://www.cdc.gov/eval/logicmodels/index.htm

Children's Therapy \& Family Resource Centre. (2011). Milestones. Retrieved from www.kamloopschildrenstherapy.org/developmental-milestones

Cole, M., \& Tufano, R., (2008). Chapter 9: Ecology of human performance. Applied Theories in Occupational Therapy: A Practical Approach. Thorofare, NJ: SLACK Inc.

Department of Defense [DoD] \& Agency for Healthcare Research and Quality [AHRQ]. (2012). The ten steps of action planning [PDF file]. Retrieved October 18, 2019 from https://www.ahrq.gov/sites/default/files/wysiwyg/professionals/education/curriculumtools/teamstepps/instructor/essentials/implguide_0.pdf

Doggett, L. \& Smith, J. (2019). H.R.3127: Home Health Flexibility Act. Retrieved March 31, 2020 from https://www.congress.gov/bill/116th-congress/house-bill/3127

Dunn, W., Brown, C., \& McGuigan, A. (1994). The Ecology of Human Performance: A framework for considering the effect of context. American Journal of Occupational Therapy 48, 595-607. https://doi:10.5014/ajot.48.7.595

Ertem, I. O., Atay, G., Dogan, D. G., Bayhan, A., Bingoler, B. E., Gok, C. G., ...Isikli, S. (2007). Mothers' knowledge of young child development in a developing country. Child: care, health and development, 33(6), 728-737. 
Fields, J. (2017). Program development, implementation, and evaluation [PowerPoint slides]. Retrieved from https://www.michiganrc.org/docs/FIELDS_Program_Development_Implementation_and_Evaluation_03.pdf

Fleming-Castaldy, R.P. \& Patro, J. (2012). Leadership in occupational therapy: Self-perceptions of occupational therapy managers. Occupational Therapy in Health Care, 26(2-3), 187202. https://doi.org/10.3109/07380577.2012.697256

Heard, C. P. (2014). Choosing the path of leadership in occupational therapy. The Open Journal of Occupational Therapy, 2(1), 2.

Heard, C. P., \& Scott, J. (2018). Informal leadership in the clinical setting: Occupational therapist perspectives. Open Journal of Occupational Therapy (OJOT), 6(2), 1-13. https://doi.org/10.15453/2168-6408.1427

Lai, W.W. \& Oei, T.P. (2014). Coping in parents and caregivers of children with autism spectrum disorder (ASD): A review. Review Journal of and Developmental Disorders, 1(3), 207-224. https://doi.org/10.1007/s40489-014-0021-x

Lapointe, J., Baptiste, S., von Zweck, C. M., \& Craik, J. M. (2013). Developing the occupational therapy profession through leadership and mentorship: Energizing opportunities. World Federation of Occupational Therapists Bulletin, 68(1), 38-43.

Ledlow, G.R., \& Stephens, J.H. (2018). Leadership for health professionals $\left(3^{\text {rd }}\right.$ ed.). Burlington, MA: Jones \& Bartlett Learning.

Lunenburg, F. C. (2011). Leadership versus management: A key distinction —at least in theory. International Journal of Management, Business, and Administration, 14(1), 1-4.

Oliver, S. (2006). Leadership in health care. Musculoskeletal Care, 4(1), 38-47. 
Ostrove, B. (2015). Administration \& management. American Occupational Therapy Association [AOTA], 31(3), 1-3.

Phipps, S. (August 2015). Transformational and visionary leadership in occupational therapy management and administration [PDF file]. Occupational Therapy Practice 20(15). Retrieved from https://www.alota.org/assets/docs/Conference2018/Transformational\%20and\%20Visiona ry\%20Leadership\%20AOTA\%20OT\%20Practice\%20Shawn\%20Phipps\%20PhD\%20MS \%20OTRL\%20FAOTA\%20\%2818\%29.pdf

Smallfield, S., Flanigan, L., \& Sherman, A. (2019). Comparing outcomes of entry-level degrees from one occupational therapy program. Journal of Occupational Therapy Education, 3(1), 7.

Smith, A. (2003). Facilitative leadership. Retrieved March 19, 2020 from https://www.grad.ubc.ca/current-students/professional-development/facilitativeleadership

Stover, A. (2016). Client-centered advocacy: Every occupational therapy practitioner's responsibility to understand medical necessity. American Journal of Occupational Therapy, 70(5). https://doi.org/10.5014/ajot.2016.705003

Toal-Sullivan, D. (2006). New graduates' experiences of learning to practise occupational therapy. British Journal of Occupational Therapy, 69(11), 513-524.

Toseland, R.W. (2004). Caregiver education and support programs: Best practice models. Retrieved from https://www.caregiver.org/sites/caregiver.org/files/pdfs/Education_Monograph_01-2005.pdf 
Truskowski, S. (2017). Leadership within occupational therapy: A mixed methods study. Leadership Within Occupational Therapy: A Mixed Methods Study, 1. Retrieved from http://search.ebscohost.com/login.aspx?direct=true \&db=ccm\&AN=130385132\&site=eds -live

Weberg, D. (2012). Complexity leadership: A healthcare imperative. Nursing forum, 47(4), 268277. 


\author{
Appendix A \\ Parent/Caregiver Education Program \\ Developmental Milestones Pre-Questionnaire
}

Directions: Below is a list of multiple-choice questions about developmental milestones for children from newborn to 6-years-old. Circle the correct answer. These developmental milestones will be reviewed in the videos over the course of the next 6-weeks. Thank you for taking your time to participate in this knowledge check.

1. When should caregivers begin to look at children's' books with their children?
a) $2-3$ months
b) $4-6$ months
c) 3-4 months
d) $9-12$ months

2. When should caregivers begin to give children a spoon or fork to let them eat by themselves?
a) 9-12 months
b) $10-15$ months
c) $12-24$ months
d) 4-6 months

3. When do children begin to grasp tiny things like raisins, with their fingertips?
a) $4-6$ months
b) $12-24$ months
c) $7-9$ months
d) 3-4 months

4. When do children begin to play imaginary play like feeding a doll or driving a car?
a) 4-6 months
b) $9-12$ months
c) $12-24$ months
d) 7-9 months

5. When should caregivers begin to give children paper and crayons to draw and color?
a) 4-6 months
b) $9-12$ months
c) $12-24$ months
d) 7-9 months

6. When should caregivers begin to let children sit with support?
a) $1-2$ months
b) 3-4 months
c) 5-6 months
d) 7-9 months 
7. When should caregivers begin to give children clean and safe objects or toys, which they can mouth?
a) $2-3$ months
b) $4-6$ months
c) $7-9$ months
d) $12-24$ months

8. When should children be able to use the toilet on his/her own independently?
a) 2 years old
b) 3 years old
c) 4 years old
d) 5 years old

9. When should children point to things or pictures when they are named?
a) 6-12 months
b) 18 months
c) 2 years
d) $3-4$ years

10. When should children begin to sort shapes and colors?
a) 12 months
b) 18 months
c) 2 years
d) 4 years

11. When should children be able to help undress him/herself?
a) $18-24$ months
b) $2-3$ years
c) $4-5$ years
d) 6 years

12. When should children start to use things correctly, for example, drinks from a cup, brushes hair?
a) 12 months
b) 2 years
c) 3 years
d) 4 years

13. When should children be able to do a puzzle with 3 or 4 pieces?
a) $6-12$ months
b) $12-24$ months
c) $2-3$ years
d) 3-4 years

14. When should children be able to pick things up like cereal o's between thumb and index finger? 

a) 6 months
b) 9 months
c) 12 months
d) 18 months

15. When should children begin to use one hand consistently for fine motor tasks?
a) $2-3$ years
b) $3-4$ years
c) $4-5$ years
d) $5-6$ years

16. When should children be able to open packages by him/herself?
a) $2-3$ years
b) $3-4$ years
c) $4-5$ years
d) $5-6$ years

17. When should a child be able to cut across a piece of paper?
a) 2 years
b) 3 years
c) 4 years
d) 5 years

18. When should a child be able to draw straight lines and circles?
a) $6-12$ months
b) 18 months
c) $2-3$ years
d) $4-5$ years

19. When do children begin to put things into containers (with large openings) and take them out?
a) $4-6$ months
b) $8-12$ months
c) 18 months
d) $2-3$ years

20. When should children be able to manage large buttons (i.e., button and unbutton)?
a) 9-12 months
b) $2-3$ years
c) $4-5$ years
d) 6 years 


\author{
Appendix B \\ Parent/Caregiver Education Program \\ Developmental Milestones Post-Questionnaire
}

Directions: Below is a list of multiple-choice questions about developmental milestones for children from newborn to 6-years-old. Circle the correct answer. These developmental milestones were reviewed in the videos over the past 6-weeks. Thank you for taking your time to participate in this knowledge check.

1. When should children be able to help undress him/herself?
e) 6 years
f) $4-5$ years
g) $2-3$ years
h) $18-24$ months

2. When should caregivers begin to look at children's' books with their children?
e) $9-12$ months
f) 3-4 months
g) $2-3$ months
h) $4-6$ months

3. When should children be able to manage large buttons (i.e., button and unbutton)?
e) 6 years
f) $4-5$ years
g) $9-12$ months
h) $2-3$ years

4. When should caregivers begin to give children a spoon or fork to let them eat by themselves?
e) $9-12$ months
f) $12-24$ months
g) $4-6$ months
h) $10-15$ months

5. When should children start to use things correctly, for example, drinks from a cup, brushes hair?
e) 4 years
f) 12 months
g) 3 years
h) 2 years

6. When do children begin to play imaginary play like feeding a doll or driving a car?
e) 4-6 months
f) 7-9 months
g) $12-24$ months
h) 9-12 months 
7. When should a child be able to draw straight lines and circles?
e) 18 months
f) $6-12$ months
g) $4-5$ years
h) $2-3$ years

8. When should caregivers begin to give children paper and crayons to draw and color?
e) $12-24$ months
f) $4-6$ months
g) $9-12$ months
h) $7-9$ months

9. When should children be able to pick things up like cereal o's between thumb and index finger?
e) 9 months
f) 18 months
g) 12 months
h) 6 months

10. When do children begin to put things into containers (with large openings) and take them out?
e) $2-3$ years
f) 4-6 months
g) 18 months
h) $8-12$ months

11. When should caregivers begin to give children clean and safe objects or toys, which they can mouth?
e) $2-3$ months
f) $12-24$ months
g) $7-9$ months
h) 4-6 months

12. When should children be able to open packages by him/herself?
e) $5-6$ years
f) $4-5$ years
g) $3-4$ years
h) $2-3$ years

13. When should children point to things or pictures when they are named?
e) 6-12 months
f) 18 months
g) 3-4 years
h) 2 years 
14. When should children begin to sort shapes and colors?
e) 2 years
f) 4 years
g) 12 months
h) 18 months

15. When should children be able to do a puzzle with 3 or 4 pieces?
e) $2-3$ years
f) $3-4$ years
g) $6-12$ months
h) $12-24$ months

16. When should children begin to use one hand consistently for fine motor tasks?
e) $4-5$ years
f) $5-6$ years
g) $2-3$ years
h) $3-4$ years

17. When should caregivers begin to let children sit with support?
e) $1-2$ months
f) 5-6 months
g) 3-4 months
h) $7-9$ months

18. When should children be able to use the toilet on his/her own independently?
e) 5 years old
f) 4 years old
g) 3 years old
h) 2 years old

19. When should a child be able to cut across a piece of paper?
e) 5 years
f) 4 years
g) 3 years
h) 2 years

20. When do children begin to grasp tiny things like raisins, with their fingertips?
e) 7-9 months
f) 3-4 months
g) $12-24$ months
h) 4-6 months 